CARNETS OE Carnets de géographes

GÉOGRAPHES.

\title{
Nouvelles centralités et recompositions socio- spatiales dans le Grand Sanaa (Yémen)
}

\section{Roman Stadnicki}

\section{(2) OpenEdition}

1 Journals

Édition électronique

URL : http://journals.openedition.org/cdg/2945

DOI : $10.4000 /$ cdg. 2945

ISSN : 2107-7266

Éditeur

UMR 245 - CESSMA

Référence électronique

Roman Stadnicki, « Nouvelles centralités et recompositions socio-spatiales dans le Grand Sanaa (Yémen) », Carnets de géographes [En ligne], 2 | 2011, mis en ligne le 02 mars 2011, consulté le 07 mai 2019. URL : http://journals.openedition.org/cdg/2945; DOI : 10.4000/cdg.2945

Ce document a été généré automatiquement le 7 mai 2019.

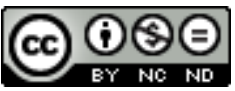

La revue Carnets de géographes est mise à disposition selon les termes de la Licence Creative Commons Attribution - Pas d'Utilisation Commerciale - Pas de Modification 4.0 International. 


\title{
Nouvelles centralités et recompositions socio-spatiales dans le Grand Sanaa (Yémen)
}

\author{
Roman Stadnicki
}

1 La ville de Sanaa, capitale du Yémen, connaît depuis le début des années 1970 une croissance urbaine fulgurante générant des dynamiques territoriales inédites. Ces dernières ont aujourd'hui pour principal théâtre les espaces périphériques, voire certaines marges physiques de l'agglomération. On assiste notamment à l'émergence de centralités périurbaines qui se démarquent à la fois par leur capacité à attirer les activités économiques et à se constituer en espaces-clés de la vie sociale. Cette thèse analyse la fabrique et la pratique de ces nouveaux centres, dont la mise en place modifie autant la structure générale du Grand Sanaa que les rapports identitaires de la société urbaine à son espace.

2 Pour ce faire, nous avons examiné en premier lieu les processus généraux de l'évolution contemporaine de l'urbanisation de Sanaa - dont les migrations, les dynamiques marchandes mais aussi, dans une moindre mesure, la mise en place d'une administration moderne, sont des composantes essentielles -, afin de comprendre quelles sont précisément les conditions d'émergence de ces centralités périphériques.

3 Nous avons procédé ensuite à l'identification de dix nouveaux centres dans l'agglomération sanaanie. Cela a consisté, d'une part, à restituer les éléments du paysage morpho-fonctionnel de ces quartiers, en insistant sur les lieux où sont implantées les fonctions motrices, à savoir les souks, les autres activités marchandes, les activités de service polarisantes et les gares routières - indices récurrents de centralité. D'autre part, nous avons fait l'examen, à partir d'entretiens semi-directifs, des stratégies d'acteurs qui ont œuvré pour la transformation de ces quartiers périphériques en véritables pôles de développement composites à fort potentiel de centralité. Produites, à l'origine, par les initiatives privées et les stratégies des "citadins ordinaires ", ces nouvelles centralités semblent aujourd'hui redéfinir l'ensemble des «identités d'action ». C'est, autrement dit, l'ensemble de la communauté des acteurs de la production urbaine qui semble 
aujourd'hui tourné vers les franges de l'agglomération, dont la polarisation à l'échelle de la capitale ne cesse de se renforcer.

4 Nous avons enfin cherché à montrer que l'évolution des pratiques (et des représentations) relève d'une véritable stratégie de conquête des espaces périphériques par les citadins, qu'elle leur donne une réelle épaisseur sociale et qu'elle produit des espaces signifiants. En investissant pleinement les dimensions sociales et symboliques des centralités émergentes à Sanaa, nous avons pu voir qu'il s'y invente aujourd'hui de nouveaux cadres d'urbanité. Cette thèse tente d'en préciser les fondements.

En variant les échelles d'observation, nous avons pu juger de l'étendue des recompositions socio-spatiales qui se réalisent au travers des nouvelles centralités de l'agglomération sanaanie. Ces dernières présentent aujourd'hui de nouveaux accès à Sanaa, révélant à la fois les potentialités diverses de l'urbain et les aspects du changement social. Ces nouveaux centres sont des lieux en mouvement, des lieux en devenir. Il s'y reforme une société urbaine mixte et contrastée, aux références multiples, preuve des hybridations architecturales, sociales et identitaires qui émergent de ces formations socio-spatiales. Elles sont analysées dans cette thèse comme le produit de la société citadine dans toute son hétérogénéité.

Dâris, centralité émergente au nord de Sanaa : marchands et badauds à l'entrée du souk au qât (plante euphorisante mâchée par une grande majorité de Yéménites)

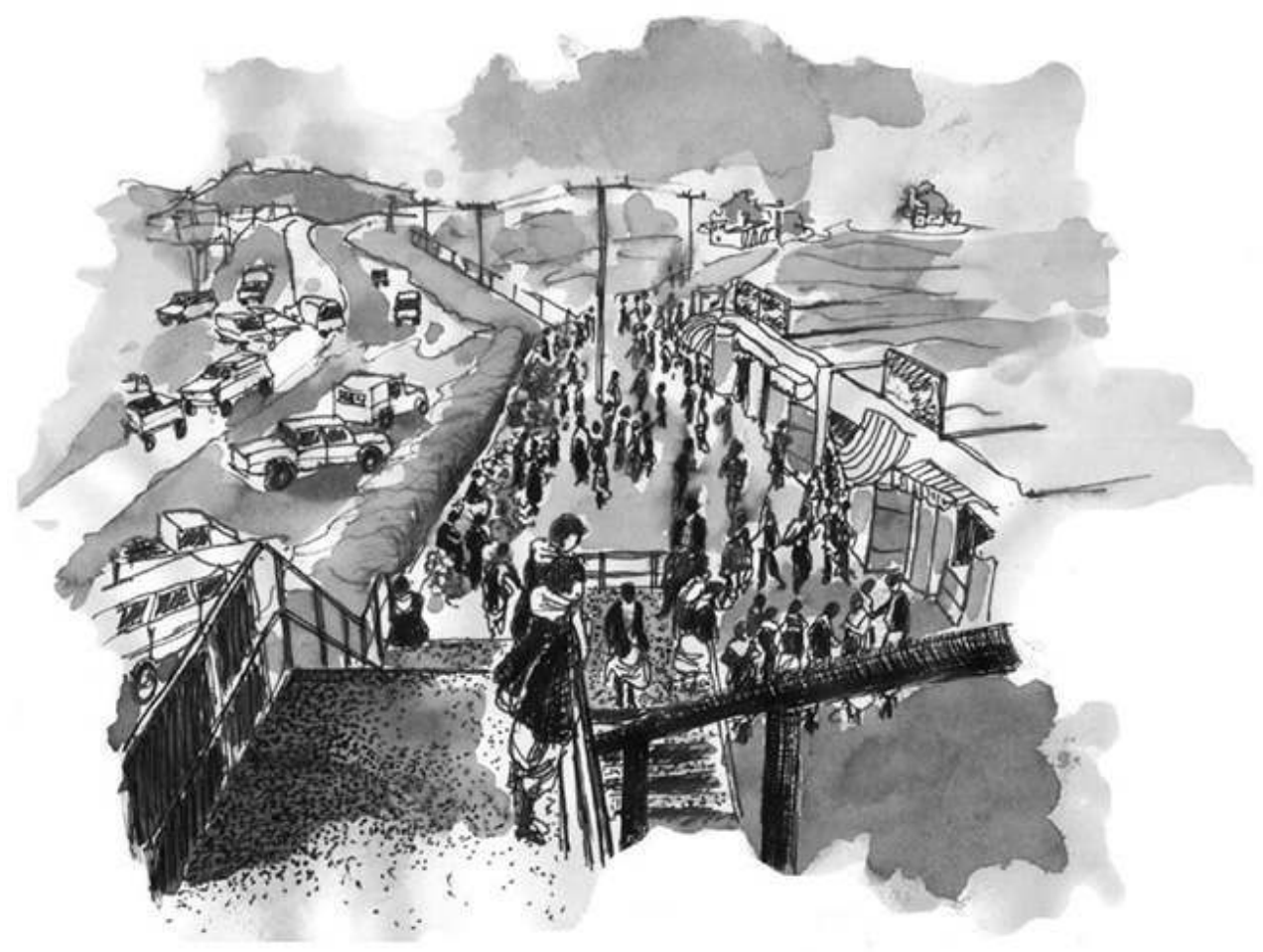

R. Stadnicki \& F. Stadnicka, 2009.

Lien électronique si la thèse est disponible en ligne http://tel.archives-ouvertes.fr/docs/00/44/94/84/PDF/ R._Stadnicki_2009_Nouvelles_centralites_et_recompositions_sociospatiales_dans_le_Grand_Sanaa_Yemen_.pdf 
Discipline

Géographie sociale

\section{Directeur}

Pierre Signoles, Professeur émérite

\section{Université}

Université François-Rabelais (Tours)

Membres du jury de thèse, soutenue le 16 novembre 2009

Robert Escallier, Université de Nice Sophia-Antipolis (rapporteur)

Anna Madœuf, Université de Tours

Franck Mermier, CNRS

Jérôme Monnet, Institut Français d'Urbanisme (rapporteur)

Pierre Signoles, Université de Tours

Jean-François Troin, Université de Tours

\section{Contact de l'auteur}

stadnicki.r@gmail.com

INDEX

Thèmes : Carnets de soutenances 